\title{
The prevalence of ocular diseases among individuals referring to the ocular emergency unit of Moradi Hospital of Rafsanjan, Iran: 2015
}

\author{
Taghavi Y, MD ${ }^{1}$, Soleimani MR, MD ${ }^{1 *}$, Mokhtaree MR, MSc ${ }^{2}$, Taheri A, Medical Student ${ }^{3}$ \\ 1- Assistant Prof., Dept. of Ophthalmology; Non-Communicable Disease Research Center, Rafsanjan University of Medical \\ Sciences, Rafsanjan, Iran. 2- Msc of Educational Psychology, Social Determeinants of Health Research Center, Rafsanjan \\ University of Medical Sciences, Rafsanjan, Iran. 3- Medical Student, Rafsanjan University of Medical Sciences, Rafsanjan, \\ Iran.
}

\begin{abstract}
Received: December 2016, Accepted: June 2017

Background: The determination of common diseases in a region is a medical and health priority of that region. Ocular emergencies can cause permanent vision loss if they are not recognized and treated promptly. Preserve vision of patients, We arranged this study in Moradi hospital (Kerman, Iran), to estimate our regional situation.

Materials and Methods: In this cross-sectional study, 2035 medical records of individuals referring to the ocular emergency unit of Moradi Hospital in 2015-2016 were assessed. Demographic information and type of injury, , were recorded in a checklist. The data were analyzed using chisquare and Fisher's exact tests.

Results: The mean age of the patients was $35.49 \pm 13.69$ years and the mean duration of time between occurrence of injury and referral was $2.59 \pm 2.11$ hours. In addition, 1902 (93.5\%) participants were men The most common object causing injury was wood $(0.8 \%)$ and chemical agent was acidic substances $(0.8 \%)$. The causes of referral in order of frequency were ocular foreign body (OFB) $(91.4 \%)$, lacerations $(3.1 \%)$, chemical burns $(1 \%)$, corneal abrasion $(0.9 \%)$, glaucoma $(0.8 \%)$, orbital cellulitis $(0.6 \%)$, thermal burns $(0.6 \%)$, infection $(0.5 \%)$, artery occlusion $(0.5 \%)$, corneal laceration $(0.4 \%)$, hyphema $(0.2 \%)$, and injuries caused by welding $(0.2 \%)$. corneal laceration, $\mathrm{OFB}$, corneal abrasion, glaucoma, and infection, lacerations, artery occlusion, and penetrating trauma more in men and $16-39$ years $(\mathrm{P}<0.05)$.

Conclusions: the majority of injuries were observed in men due to ocular foregin body related to occupational practice. Therefore, occupational ocular injuries should be reduced through a closer relationship between medicine and industries, and education on occupational accidents.
\end{abstract}

Keywords: Eye, Emergency, Trauma, Burn, Iran.

\section{Introduction}

The eyes and their related diseases is one of the major topics in medicine and general practitioners and specialists will be faced with its related issues repeatedly during the course of their professional career. Emergency eye patients are an important group of clients of specialist and general emergency units. Some of these diseases are potentially sightthreatening and, in the absence of appropriate treatment, may leave lesions in the eye and will impose many social and economic damages. The majority of eye diseases are preventable and treatable through the correct treatment methods (1). Therefore, the evaluation of the prevalence of each of these diseases and disorders is necessary in order to make appropriate plans to allocate suitable educational facilities and required medical facilities (1).

\footnotetext{
* Corresponding author: Mohammadreza Soleimani, Dept. of Ophthalmology; Non-Communicable Disease Research Center, Rafsanjan University of Medical Sciences, Rafsanjan, Iran.

E-mail: dr.solimani@rums.ac.ir
} 
Ocular emergencies include ocular trauma, infection, ocular foreign body (OFB), vascular issues, chemical and thermal burns, and impaired intraocular pressure (IOP) $(2,3)$. Ocular trauma is one of the common causes of unilateral blindness in children and adolescents and one of the important causes of reduced vision in adults. Statistics show that 1 out of every 20 individuals who refer to the ophthalmologist refer due to ocular trauma (2). In thermal burns, usually, the eyelids are initially affected. Ultraviolet burns are mostly observed in welders, skiers, and those exposed to Ultar violet light bulbs. Chemical burns, especially with alkaline substances, are the most urgent optometry cases due to the rapid penetration of these materials into the eye tissue (4). Penetrating traumas are common emergencies which are accompanied by intraocular hemorrhage, corneal laceration, and globe rupture (5). Corneal laceration requires immediate treatment due to the risk of damage to the internal structures of the eye and infection (4). OFBs consist of particles of metal, glass, wood, stone, and other materials which can cause irreparable injury in surface and deep ocular structures (6). Sudden loss of vision is another optometry emergency which requires prompt referral to the ophthalmologist. An hour delay in referral may result in the complete and irreparable loss of vision (7). The most common symptom of retinal vein and artery occlusion is the sudden and painless loss of vision. If the loss of vision is due to central retinal artery occlusion (CRAO), with the passage of 1 hour the individual's vision is permanently lost (8).

In the study by Shoja, $77 \%$ of individuals referred to the ocular emergency unit due to ocular trauma and OFB, and of this amount, $43 \%$ was related to OFB (9). The prevalence of OFB in the studies by El-mekaway (3), Jana (10), and Katibeh (11) was 99.37\%, 45.4\%, $73.7 \%$, respectively. The prevalence of corneal laceration in the studies by Eslami (12), Channa (2) was, respectively, $3.97 \%$ and $14 \%$.
Different researches have been conducted in Iran regarding ocular emergencies, but the majority of them have studied ocular injuries. Therefore, the present study was performed to determine the rate and type of injuries, diseases, and disorders identified as ocular emergencies. The analysis of the obtained data will provide researchers with an understanding of the current state so that they can make long term plans for the provision of effective solutions, and prevention and timely and speedy treatment of preventable emergencies through training the relevant personnel and medical interns. Moreover, such researches will provide authorities and employers with important information on occupational eye injuries; thus, they can reduce these injuries through systematic planning. Therefore, the results of this study can increase the awareness of families regarding eye injuries in children and adolescents and pave the way for their prevention.

\section{Material and Methods}

The study population of the present research consisted of all individuals referring to the ocular emergency unit of Moradi Hospital, Rafsanjan, Iran, in 2015 ( $\mathrm{n}=2035)$ who were selected through census method.

In the present study, medical review method was used. The names of eye patients were extracted from the hospital information system (HIS) and, using patient codes, their medical records were retrieved from the archives and their information was reviewed. A checklist designed to collect data was completed based on these findings. It must be noted that incomplete medical records were excluded from the study.

The study checklist consisted of demographic characteristics (such as age, gender, education, and residency area) and ocular injury characteristics (type of injury, the substance causing the injury, the duration of time between the occurrence of the injury and 
referral, the treatment type performed in the emergency unit, the hospitalization or discharge status of the patient). Moreover, ocular infections were recorded in the checklist based on the clinical diagnosis recorded in the patients' medical records. The collected data were entered into SPSS software (version 16, SPSS Inc., Chicago, IL, USA) and the results related to the quantitative and qualitative variables are reported as mean $\pm \mathrm{SD}$ and number (\%), respectively. In addition, chi-square and Fisher's exact tests were used to assess the relationship between the variable and the significance level was considered as 0.05 in the tests.

\section{Results}

In total, the medical records of 2035 patients with a mean age of $35.49 \pm 13.67$ years (in the range of 1-90 years) were evaluated. The mean duration of time between occurrence of injury and referral was $2.59 \pm 2.11$ hours, in the range of 1-35 hours. Among them, 1902 individuals (93.5\%) were men, 1974 (97\%) were Iranian, 1372 (76.4\%) lived in the city, 1333 (65.5\%) had a diploma, and 1698 (83.4\%) had insurance. The highest number of referrals were in July-August (193 individuals, 9.5\%) and the lowest number in SeptemberOctober (142 individuals, 7\%).

Table 1: Frequency of hyphema, penetrating trauma, corneal abration, corneal laceration, and laceration in other components of the eye based on age and gender

\begin{tabular}{cccccc}
\hline Group & $\begin{array}{c}\text { Hyphema } \\
(\mathbf{n}=\mathbf{4})\end{array}$ & $\begin{array}{c}\text { Penetrating } \\
\text { trauma } \\
(\mathbf{n}=\mathbf{4 0})\end{array}$ & $\begin{array}{c}\text { Corneal } \\
\text { abration } \\
(\mathbf{n}=\mathbf{1 9})\end{array}$ & $\begin{array}{c}\text { corneal } \\
\text { laceration } \\
(\mathbf{n}=\mathbf{8})\end{array}$ & $\begin{array}{c}\text { laceration in other } \\
\text { components of the eye } \\
(\mathbf{n}=\mathbf{6 4})\end{array}$ \\
\cline { 2 - 5 } & $\mathbf{N}(\mathbf{\%})$ & $\mathbf{N}(\mathbf{\%})$ & $\mathbf{N}(\mathbf{\%})$ & $\mathbf{N}(\mathbf{\%})$ & $\mathbf{N}(\mathbf{\%})$ \\
\hline Men & $4(100)$ & $33(82.5)$ & $14(73.7)$ & $5(62.5)$ & $54(84.4)$ \\
\hline Women & 0 & $7(17.5)$ & $5(26.3)$ & $3(37.5)$ & $10(15.6)$ \\
\hline Total & $4(100)$ & $40(100)$ & $19(100)$ & $8(100)$ & $64(100)$ \\
\hline $\begin{array}{c}\text { Result of statistical test } \\
\text { Fisher's exact test) }\end{array}$ & $\mathrm{p}=1$ & $\mathrm{p}=0.013$ & $\mathrm{p}=0.006$ & $\mathrm{p}=0.012$ & $\mathrm{p}=0.007$ \\
\hline $\mathbf{1 - 1 5}$ years of age & $1(25)$ & $13(32.5)$ & $1(5.3)$ & $2(25)$ & $21(32.8)$ \\
\hline $\mathbf{1 6 - 3 9}$ years of age & $3(75)$ & $15(37.5)$ & $12(63.2)$ & $3(37.5)$ & $26(40.6)$ \\
\hline Over 40 years of age & 0 & $12(30)$ & $6(31.6)$ & $3(37.5)$ & $17(26.6)$ \\
\hline Total & $4(100)$ & $40(100)$ & $19(100)$ & $8(100)$ & $64(100)$ \\
\hline Result of statistical test & $\mathrm{p}=0.1$ & $\mathrm{p}<0.001$ & $\mathrm{p}=0.995$ & $\mathrm{p}=0.026$ & $\mathrm{p}<0.001$ \\
\hline
\end{tabular}

Regarding the object causing the injury, 4 $(0.2 \%), 17(0.8 \%)$, and $5(0.2 \%)$ individuals were injured with a knife, wood, and stone, respectively, and $40(2 \%)$ individuals had a penetrating trauma. Moreover, 21 individuals (1\%) had chemical burns, and among this group, $17(0.8 \%)$ and $4(0.2 \%)$ individuals were injured with acidic and alkaline substances, respectively. Among the referrals to the emergency unit, $13(0.6 \%)$ individuals had thermal burns (caused by exposure to direct flame or steam from boiling substances) and $5(0.2 \%)$ individuals had injuries caused by welding. Regarding the type of disorder, 4 (0.2\%), 8 (0.4\%), 64 (3.1\%), $12(0.6 \%), 19$ $(0.9 \%), 11(0.5 \%), 10(0.5 \%)$, and $16(0.8 \%)$ individuals had a hyphema, corneal laceration, laceration in other components of the eye, orbital cellulitis, corneal abrasion, ocular infection, retinal artery occlusion, and glaucoma, respectively. OFB was the cause of the referral of 1860 (91.4\%) individuals to the emergency unit. In total, 48 (2.4\%) cases of ocular emergency resulted in hospitalization.

Data analysis showed that penetrating trauma, corneal abration, corneal laceration, laceration in other components of the eye (Table 1), OFB, retinal artery occlusion, ocular infection, glaucoma, and cases resulting in hospitalization (Table 2) were significantly higher in men $(\mathrm{P}<0.05)$. 
Table 2: Frequency of orbital cellulitis, ocular foreign body, retinal artery occlusion, glaucoma, infection, and cases resulting in hospitalization based on age and gender

\begin{tabular}{ccccccc}
\hline Group & $\begin{array}{c}\text { Orbital } \\
\text { cellulitis } \\
(\mathbf{n}=\mathbf{1 2})\end{array}$ & $\begin{array}{c}\text { ocular } \\
\text { foreign body } \\
(\mathbf{n = 1 8 6 0 )}\end{array}$ & $\begin{array}{c}\text { Retinal artery } \\
\text { occlusion } \\
(\mathbf{n}=\mathbf{1 0})\end{array}$ & $\begin{array}{c}\text { Glaucoma } \\
(\mathbf{n}=\mathbf{1 6})\end{array}$ & $\begin{array}{c}\text { Infection } \\
(\mathbf{n}=\mathbf{1 1})\end{array}$ & $\begin{array}{c}\text { Hospitalization } \\
(\mathbf{n}=\mathbf{4 8})\end{array}$ \\
\cline { 2 - 7 } $\mathbf{N}(\boldsymbol{\%})$ & $\mathbf{N}(\boldsymbol{\%})$ & $\mathbf{N}(\boldsymbol{\%})$ & $\mathbf{N}(\boldsymbol{\%})$ & $\mathbf{N}(\boldsymbol{\%})$ & $\mathbf{N}(\boldsymbol{\%})$ \\
\hline Men & $11(91.7)$ & $1780(95.7)$ & $7(70)$ & $4(25)$ & $6(54.5)$ & $36(75)$ \\
\hline Women & $1(8.3)$ & $80(4.3)$ & $3 .(30)$ & $12(75)$ & $5(45.5)$ & $12(25)$ \\
\hline Total & $12(100)$ & $1860(100)$ & $10(100)$ & $16(100)$ & $11(100)$ & $48(100)$ \\
\hline $\begin{array}{c}\text { Result of statistical test } \\
\text { (Fisher's exact test) }\end{array}$ & $\mathrm{p}=0.557$ & $\mathrm{p}<0.001$ & $\mathrm{p}=0.023$ & $\mathrm{p}<0.001$ & $\mathrm{p}<0.001$ & $\mathrm{p}<0.001$ \\
\hline $\mathbf{1 - 1 5}$ years of age & $1(8.3)$ & $68(3.7)$ & 0 & 0 & 0 & $4(8.3)$ \\
\hline $\mathbf{1 6 - 3 9}$ years of age & $5(41.7)$ & $1209(65)$ & $5(50)$ & $1(6.3)$ & $5(45.5)$ & $24(50)$ \\
\hline Over 40 years of age & $6(50)$ & $583(31.3)$ & $5(50)$ & $15(93.8)$ & $6(54.5)$ & $20(41.7)$ \\
\hline Total & $12(100)$ & $1860(100)$ & $10(100)$ & $16(100)$ & $11(100)$ & $48(100)$ \\
\hline Result of statistical test & $\mathrm{p}=0.327$ & $\mathrm{p}<0.001$ & $\mathrm{p}=0.428$ & $\mathrm{p}<0.001$ & $\mathrm{p}=0.257$ & $\mathrm{p}=0.168$ \\
\hline
\end{tabular}

Furthermore, penetrating trauma, ocular laceration, laceration in other components of the eye (Table 1), OFB (Table 2), and thermal burns (Table 3 ) were significantly higher in the age group of $16-39$ years $(\mathrm{P}<0.05)$. However, glaucoma was higher among women and the age group of over 40 years $(\mathrm{P}<0.001)$ (Table 2).

Table 3: Frequency distribution of different types of burns and injuries caused by welding based on age and

\begin{tabular}{cccc}
\hline \multirow{2}{*}{ Group } & $\begin{array}{c}\text { Chemical burns } \\
(\mathbf{n}=\mathbf{2 1})\end{array}$ & $\begin{array}{c}\text { Thermal burns } \\
(\mathbf{n = 1 3})\end{array}$ & $\begin{array}{c}\text { Welding } \\
(\mathbf{n}=\mathbf{5})\end{array}$ \\
\cline { 2 - 4 } & $\mathbf{N}(\mathbf{\%})$ & $\mathbf{N}(\mathbf{\%})$ & $\mathbf{N}(\mathbf{\%})$ \\
\hline Men & $21(100)$ & $11(84.6)$ & $5(100)$ \\
\hline Women & 0 & $2(15.4)$ & 0 \\
\hline Total & $21(100)$ & $13(100)$ & $5(100)$ \\
\hline $\begin{array}{c}\text { Result of statistical test } \\
\text { (Fisher's exact test) }\end{array}$ & $\mathrm{P}=0.394$ & $\mathrm{P}=0.207$ & $\mathrm{P}=0.713$ \\
\hline $\mathbf{1 - 1 5}$ years of age & $1(4.8)$ & $2(15.4)$ & 0 \\
\hline $\mathbf{1 6 - 3 9}$ years of age & $12(57.1)$ & $11(84.6)$ & $5(100)$ \\
\hline Over 40 years of age & $8(38.1)$ & 0 & 0 \\
\hline Total & $21(100)$ & $13(100)$ & $\mathrm{p}=0.222$ \\
\hline Result of statistical test & $\mathrm{p}=0.860$ & $\mathrm{p}=0.017$ & $(100)$ \\
\hline
\end{tabular}

\section{Discussion}

The results of the present study showed that $93.5 \%$ of patients were men. The prevalence of men in other studies was $96 \%$ (11), $81.7 \%$ (13), and $54.2 \%$ (2). This high incidence was mainly due to occupation. In most countries, men perform difficult occupations which require industrial tools in the open air or polluted environments; thus, the rate of occupational eye injuries, like other occupational injuries, are higher among them (14).
In the present study, the mean age of patients was $35.49 \pm 13.79$ years, in the range of 1-90 years. In addition, $62.5 \%$ of patients referring to the ocular emergency units were in the range of 16-39 years of age. In most previous studies, the majority of patients referring to the ocular emergency units were in this age range $(2,9,11$, and 15). Individuals perform the majority of their occupational and professional activities over the age of 30 ; therefore, it is predictable that most occupational injuries, 
such as ocular injury, occur in this age range (16).

In the present study, the most common emergency was OFB with the prevalence of 91.4\%. In studies conducted in Egypt (3), the USA (2), India (10), and Tehran (11), Tabriz (17), and Kashan, Iran (18), the prevalence of OFB was $99.37 \%, 7.5 \%, 45.4 \%, 72.7 \%$, $79.7 \%, 55 \%$, respectively.from this view, the result of the present study was in compatible with other studies, although it was higher than most of them., in addition dust can cause OFB due to desert type of our region.

A cause of the high prevalence of OFB in the present study, compared to previous studies, in the desert region of Rafsanjan, Iran, was the dispersion of dust due to seasonal winds and the dry air of the region, and its penetration into the eyes (19). Furthermore, occupation is one of the factors which impact the occurrence of most ocular emergencies such as OFB. Therefore, the use of eye protection equipment in industries must be increased through creating a safety culture or made compulsory. Ocular injuries may be sharp and penetrating (penetration and laceration) or blunt (injuries that cause the crushing and laceration of intraocular components without the object penetrating the eye) or intraocular injuries may occur through OFB (bullet, glass, stone, and etcetera) $(20,21)$. The most common damaging objects reported by patients in the present study were wood, stone, and knife, respectively. This finding was in accordance with that of the studies by Asalkho (22), and Dehghani (23).

The prevalence of corneal laceration in the present study was $0.4 \%$. The prevalence of corneal laceration in Kashan, Iran (24), Isfahan, Iran (25), and Cairo, Egypt (3), was, respectively, $18.6 \%, 1.3 \%$, and $4.6 \%$.

Furthermore, in the present study, $16.7 \%$ of all hospitalized cases were due to corneal laceration; this rate was $77.3 \%$ and $23.2 \%$ in the studies by Abdellahi (26) and Norouzpour (27), respectively. Corneal laceration is very dangerous due to the possibility of intraocular infection in and damage to the inner structure of the eye (28).

In our study, $1 \%$ of all emergency cases had chemical burns, of this amount, $0.8 \%$ of burns were due to acidic substances and $0.2 \%$ due to alkaline substances. In Jafarinasab study, the rate of chemical burns was $0.86 \%$ and the majority of these cases were due to acidic substances (13), which was in agreement with the results of the present study. The prevalence of chemical burns in the study by Mansouri was $14.4 \%$ (29), which was much higher than that in the present study. In the present study, all individuals with chemical burns were men $(\mathrm{n}=21)$ and $57.1 \%$ of them were in age range of 16-39 years. This age and gender prevalence was in accordance with other studies in other parts of the world $(30,31)$. In the current study, the location of accident occurrence was not assessed. Some chemical burn cases are due to household detergents which are mostly observed in women; however, the researches have shown that most chemical burns are due to occupational incidents.

A limitation of this study was incomplete records and lack of documentation for some patients. This issue can impact the reported statistics, but considering the electronization of the hospital admission and clearance procedures, its impact is insignificant. It is suggested that future researches be conducted as prospective studies. The lack of assessment of the time and location of the occurrence of the incident and use of protection equipment was another limitation of this study; thus, it is suggested that they be evaluated in future studies.

\section{Conclusion}

In the present study, the most common cause of referral to the ocular emergency unit was OFB, especially in men, which seems to be due to occupational incidents. Moreover, the prevalence of penetrating trauma was significant in the present study. It seems that the prevalence of some ocular emergencies, 
such as corneal laceration, in Rafsanjan was somewhat less than other mentioned areas. However, the prevalence of OFB was high which was mainly due to free dust and welders' low use of eye protection equipment. Although the use of eye protection equipment was not evaluated in the present study, it is an important issue in the process of the protection of eyes from trauma.

\section{Acknowledgment}

The authors would like to thank the deputy of research of the School of Medicine, Rafsanjan University of Medical Sciences, for the financial and moral support, the chief of the Moradi Hospital for permitting the use of hospital records and statistics, and the manager of Patient Admission Center, , personel of medical records and information technology unit for access to records and statistics.

Conflict of interests: None declared.

\section{References}

1. Albert D, Miller J, Azar D, Blodi B. Albert \& Jakobiec's Principles \& Practice of Ophthalmology. $3^{\text {rd }}$ ed. Philadelphia, United States: Walter Burns Saunders Co; 2008. P.5069.

2. Channa R, Zafar SN, Canner JK, Haring RS, Schneider EB, Friedman DS. Epidemiology of eye-related emergency department visits. JAMA Ophthalmol 2016; 134(3):312-9.

3. El-Mekawey $\mathrm{HE}, \mathrm{Abu} \mathrm{El}$ Einen $\mathrm{KG}$, Abdelmaboud M, Khafagy A, Eltahawy EM. Epidemiology of ocular emergencies in the egyptian population: a five-year retrospective study. Clin Ophthalmol 2011; 5:955-60.

4. Sarabahi S, Kanchana K. Management of ocular and periocular burns. Indian Journal of Burns 2014; 22(1):22-32.

5. Scott R. The injured eye. Philos Trans R Soc Lond B Biol Sci 2011; 366(1562):251-60.

6. Clement I. Textbook on first aid \& emergency nursing. $1^{\text {st }}$ ed. New Delhi, India: Jaypee Brothers Medical Publishers; 2012. P.198.

7. Simon Ch, Everitt H, Van Drop F, Burkes M. Oxford handbook of general practice. $4^{\text {th }}$ ed. Oxford, England, United Kingdom: Oxford University press; 2014. P.972.
8. Varma DD, Cugati S, Lee AW, Chen CS. A review of central retinal artery occlusion: clinical presentation and management. Eye (Lond) 2013; 27(6):688-97.

9. Shoja MR, Rastgar A. Eye emergencies in railway hospital of Yazd. Journal of Shaeed Sdoughi University of Medical Sciences Yazd 2003; 10(4):3-9.

10. Jana S, Chaundhuri SK, Dey AK, Ganguly P, Bandopadhyay M, Dutta S. Ocular emergencies in a rural hospital: a 5 year retrospective clinical audit. Pakistan Journal of Ophthalmology 2014; 30(2):68-72.

11. Katibeh M, Rafatti N, Sehat M, Mirzadeh M, Ghasemzadeh N, Azarmina M. Evaluation of safety devices used in work-related eye injuries. Bina Journal of Ophthalmology 2009; 14(4):394-9.

12. Eslami I, Salehi A, Safdarian B, Hajian M. The epidemiological investigation of traumatic corneal laceration in the Resalat hospital, Shahrekord. Journal of Shahrekord Uuniversity of Medical Sciences 1999; 1(2):39-43.

13. Jafarinasab MR, Mirdehghan A, MohammadNashtaie E, Rabanikhah Z, Parchegani MR. Epidemiology of acute ocular chemical injury at labbafinejad medical center during 2004. Bina Journal of Ophthalmology 2011; 16(2):130-5.

14. Shaeri M, Moravveji A, Fazel MR, Rangraz Jeddi F. Status of ocular trauma in hospitalized patients in Kashan, 2011: as a sample of industrial city. Chin J Traumatol 2016; 19(6):326-9.

15. Pierre Filho PdTP, Parente Gomes PR, Linhares Pierre ÉT, Pinheiro Neto FB. Profile of ocular emergencies in a tertiary hospital from Northeast of Brazil. Rev Bras Oftalmol 2010; 69(1):12-7.

16. Serinken M, Turkcuer I, Cetin EN, Yilmaz A, Elicabuk H, Karcioglu O. Causes and characteristics of work-related eye injuries in western Turkey. Indian J Ophthalmol 2013; 61(9):497-501.

17. Mazaheri A, Mirzaie $M$, Rostami $H$. Epidemiologic survey of occupational eye injuries in emergency units. Journal of Urmia Nursing and Midwifery Faculty 2007; 5(4):4552.

18. Bagheri A, Zare M, Sehat M. Epidemiology of patients with eye trauma referred to eye clinic of Kashan, 1995. Feyz 1998; 2(1):33-47.

19. Barthold VV, Soucek S. Quhistan, Kirman, and Makran. An historical geography of Iran (princeton princeton university). $1^{\text {st }}$ ed. Princeton, New Jersey, United States: Princeton University Press; 2014. P.133-47. 
20. Al-Thowaibi A, Kumar M, Al-Matani I. An overview of penetrating ocular trauma with retained intraocular foreign body. Saudi $\mathrm{J}$ Ophthalmol 2011; 25(2):203-5.

21. Hung KH, Yang CS, Kao SC, Lee FL, Lee SM. Management of double-penetrating ocular injury with retained intraorbital metallic foreign body. J Chin Med Assoc 2011; 74(11):523-6.

22. Asalkho A. Epidemiology of eye trauma in Farabi hospital of Tehran [MD thesis]. Tehran: Tehran University of Medical Sciences; 1998.

23. Dehghani AR, Razmjo H, Kianersi F, Rezaie L, Sadoni H, Gharoie K. Epidemiologic aspects of penetrating eye trauma in subjects younger than sixteen years at feiz hospital in 2009. Bina Journal of Ophthalmology 2011; 17(1):54-9.

24. Aghadoost D, Zare M, Fazel MR, Dalirian A. Epidemiology of severe ocular injuries in Kashan, 2004. Feyz 2008; 11(5):47-50.

25. Fazel F, Akhlaghi MR, Moieni HA, Parastegary F. Epidemiology of occupationrelated ocular trauma in Esfahan. Iranian South Medical Journal 2008; 10(2):166-74.

26. Abdollahi A, Mansouri MR, Valaie N.
Epidemiologic evaluation of ophthalmic traumas in 150 patients hospitalized in Farabi hospital in Tehran. Feyz 2001; 5(1):28-32.

27. Nowroozpoor Dailami K, Sheykhrezaee MR, Kabirzadeh A, Mohseni Saravi B, Yamrali J. Prevalence and causes of eye injuries in inpatients at hospitals of the Mazandaran University of Medical Sciences in 2007-2008. Journal of Mazandaran University of Medical Sciences 2011; 21(81):77-83.

28. Sutphin JE. Basic and Clinical Science Course (BCSC) 2007-2008: External disease and cornea section 8. $1^{\text {st }}$ ed. San Francisco, United States: American Academy of Ophthalmology; 2007. P.378-420.

29. Mansouri MR, Mirshahi A, Hosseini M. Household ocular injuries: a case series. Bina Journal of Ophthalmology 2006; 12(1):89-97.

30. Xiang H, Stallones L, Chen G, Smith GA. Work-related eye injuries treated in hospital emergency departments in the US. Am J Ind Med 2005; 48(1):57-62.

31. Ho CK, Yen YL, Chang CH, Chiang HC, Shen YY, Chang PY. Epidemiologic study on workrelated eye injuries in Kaohsiung, Taiwan. Kaohsiung J Med Sci 2007; 23(9):463-9. 